\title{
Sustainability aspects and nutritional composition of fish: evaluation of wild and cultivated fish species consumed in the Netherlands
}

\author{
S. Marije Seves ${ }^{1} \cdot$ Elisabeth H. M. Temme ${ }^{1}$. \\ Marinka C. C. Brosens ${ }^{1} \cdot$ Michiel C. Zijp ${ }^{1}$. \\ Jeljer Hoekstra $^{1}$ • Anne Hollander ${ }^{1}$
}

Received: 27 March 2015 / Accepted: 4 December 2015 / Published online: 21 December 2015

(C) The Author(s) 2015. This article is published with open access at Springerlink.com

\begin{abstract}
Health councils recommend higher fish consumption because of its associated health benefits. However, overfishing is considered the main threat to marine fisheries. To answer to the global fish demand, cultivated fish production continues to grow and may come with environmental concerns. This study aims to evaluate environmental sustainability and n-3 long chain $\left(\geq \mathrm{C}_{20}\right)$ polyunsaturated fatty acids (n-3 LC-PUFA) content of current fish consumption in the Netherlands. Fish consumption was assessed on two non-consecutive days by 24-hour recalls in the Dutch National Food Consumption Survey 2007-2010 ( $n=3819$, aged $7-69 \mathrm{yr}$ ). Fish products consumed were classified according to species and types of fishery. We evaluated greenhouse gas emissions (GHGE) and land use, calculated via life cycle assessments. Fish stocks and biodiversity were taken into account via sustainability labels. Eicosapentaenoic acid (EPA) and docosahexaenoic acid (DHA) contents in fish were calculated based on analyses available from food composition databases and literature. The Dutch average consumption is 6-15 g fish per person per day, of mostly wild-caught fish. Large variations exist between fish species in GHGE and n-3 LC-PUFA contents, and are independent of the type of fishery. Land use is higher for cultivated fish. Cultivated salmon contains significantly more n-3 LC-PUFA and total fat than wild-caught salmon. For most species evaluated, except for mackerel and catfish, fish with a sustainability label is available. Our results suggest that herring, wild-caught and cultivated salmon with MSC/ASC logo are a reasonable choice from the combined perspective of n-3 LC-PUFA content and the selected environmental indicators.
\end{abstract}

Elisabeth H. M. Temme

Liesbeth.Temme@rivm.nl

1 National Institute for Public Health and the Environment (RIVM), Postbus 1, 3720 BA Bilthoven, The Netherlands 


\section{Introduction}

Coping with limited environmental resources and simultaneously feeding a growing global population in a healthy way is a major challenge (Garnett 2008). With regard to fish consumption, overfishing poses a large pressure on marine fisheries. In 2015, 7.5\% (of a total of 1220 species) of all European marine fish species are threatened with extinction. Another $2.6 \%$ are considered near threated (IUCN 2015). Existing marine management has been successful for the recovery of some fish stocks, but not yet for all (IUCN 2015). In the meantime, cultivated fish production has grown rapidly (especially in Asia) over the last decades, nowadays covering up more than $40 \%$ of the total fish supply for human food (FAO 2014). Just like wild-caught fish also cultivated fish production may have sustainability problems.

To determine the environmental impact of fish consumption, several direct and indirect indicators may be considered. For wild fisheries, direct ecosystem impacts are primarily related to overfishing, but also to by-catch and discards, seabed disruption and chemical pollution (Goñi 1998). Cultivated fish production is related to disruption of coastal ecosystems, eutrophication, chemical pollution and antibiotic use (Iwama 1991; Mirto et al. 2010; Wu 1995). Wild-caught fish is processed into fish meal and fish oil used to feed cultivated fish (Westhoek et al. 2011), but also various plant-based alternatives are used (Naylor et al. 2009). Greenhouse gas emissions (GHGE) and land use, the latter mainly for cultivated fisheries that require agricultural land (e.g., for soy production), can be considered as indirect impacts associated with energy usage, fossil fuels and terrestrial land use (Westhoek et al. 2011).

Several guidelines were developed to guide retailers and consumers towards (more) sustainable fish choices through product labelling. The Marine Stewardship Council (MSC) label for sustainable wild fisheries includes criteria for e.g., maintenance and recovery of wild fish populations and the integrity of ecosystems; thereby meeting the relevant local and national laws and standards as well as international agreements (MSC 2014b). For cultivated fish, the Aquaculture Stewardship Council (ASC) label takes into account seven principles; comprehensive legal compliance; conservation of natural habitat and biodiversity; conservation of water resources; conservation of species diversity and wild population through prevention of escapes; use of feed and other inputs that are sourced responsibly; good animal health (no unnecessary use of antibiotics and chemicals); and social responsibility for workers and communities impacted by farming (ASC 2014).

Regarding the nutritional composition, fish is an essential source of long chain $\left(\geq \mathrm{C}_{20}\right)$ polyunsaturated fatty acids (LC-PUFA); eicosapentaenoic acid (EPA) and docosahexaenoic acid (DHA). For our daily intake we largely depend on the consumption of seafood including fish (Health Council of the Netherlands 2015). Although inconsistencies in the evidence exist (Ascherio et al. 1995; He et al. 2004a, b; Osler et al. 2003; Raatz et al. 2013), a higher intake of fish is associated with a lower risk of cardiovascular diseases and mortality (He et al. 2004a, b; Raatz et al. 2013).

Recommendations for the consumption of fish and n-3 LC-PUFA intake vary, but health councils worldwide advice to consume fish because of its positive health effects. The Dutch Health Council recommends one serving of fish (preferably oily fish) per week (Health Council of the Netherlands 2015). International guidelines recommend a consumption of 250 mg n-3 LC-PUFA per day (EFSA Panel on Dietetic Products Nutrition and Allergies (NDA) 2010; FAO/WHO 2008).

Of the Dutch population, 6-28\% consumes fish twice a week, 28-65\% once a week and 5-18 \% less than once a week (Van Rossum et al. 2011). The frequency of fish consumption increases by age for both men and women (Van Rossum et al. 2011). In the Netherlands, 
current fish consumption contributes to $4 \%$ of protein intake and $22 \%$ of EPA and DHA intake. Moreover, the current fish consumption contributes to intakes of vitamin B12 (9\%), vitamin D (8 \%) and selenium (8 \%) (Van Rossum et al. 2011).

The n-3 LC-PUFA content varies according to fish species, size, season and the composition of feed (Murray and Burt 2001). Oily fish species, such as salmon, mackerel and herring, contain a high amount of fat and n-3 LC-PUFA (Strobel et al. 2012). The n-3 LC-PUFA content of cultivated fish varies according to the fish feed composition. Several studies report that cultivated fish, such as turbot, bream and crayfish, contain more fat than wild fish, whereas their n-3 LC-PUFA content was estimated lower than in similar wild fish species (Harlioğlu et al. 2012; Sérot and Gandemer 1998; Zakeri 2011). Food safety aspects, such as contaminants and antibiotics, are not taken into account in our study.

This study aims to explore a selection of environmental aspects (GHGE and land use as indirect indicator and availability of sustainability labels as more direct indicator) and n-3 LCPUFA content of different fish species and fisheries (wild, cultivated or both); and to put these aspects in the perspective of the present quantities of fish species consumed in the Netherlands.

\section{Methods}

This study combined data on the environmental aspects and nutritional composition of fish consumption. The environmental impact was estimated for the total fish consumption in the Netherlands (in g/day) as well as per fish species (in kg product). Moreover, n-3 LC-PUFA content was quantified per fish species. Consequently, the fish species were categorized in types of fishery and compared in environmental impact and n-3 LC-PUFA content.

\subsection{Current fish consumption in the Netherlands}

Consumption data of the Dutch National Food Consumption Survey (DNFCS) 2007-2010 were used to determine the consumed fish products among the Dutch population aged 7-69 years (Van Rossum et al. 2011). The food consumption of 3,819 people was assessed by two non-consecutive 24-h recalls. The recalls were equally spread over the days of the week and throughout the year, with an average interval of 4 weeks. Pregnant and lactating women and institutionalized people were excluded from the population. All fish consumed, except for shellfish, was included in this study. For shellfish, the available data on environmental impacts was limited. Most consumed fish products in the Netherlands (covering $75 \%$ of total quantity) were classified according to species and type of fishery (wild, cultivated, both/unspecified) (Fig. 1), using information of the North Sea Foundation and the MSC (MSC 2014b; North Sea and World Wide Fund for Nature 2013). Catfish was not reported in the DNFCS, but is included in the assessment, because catfish is cultivated and sold in the Netherlands (Anova Seafood 2014).

\subsection{Environmental impact of fish}

The environmental impact of fish consumption was assessed considering three indicators: greenhouse gas emissions (GHGE, $\mathrm{kg} \mathrm{CO}_{2}$-equivalents per $\mathrm{kg}$ product), land use ( $\mathrm{m}^{2} *$ year per $\mathrm{kg}$ product) and availability of MSC or ASC labels. GHGE is an indicator for global warming (Garnett 2013), and in this study covers not only carbon dioxide $\left(\mathrm{CO}_{2}\right)$ emissions, but also methane $\left(\mathrm{CH}_{4}\right)$ and nitrous oxide $\left(\mathrm{N}_{2} \mathrm{O}\right)$ emissions, which are expressed in $\mathrm{CO}_{2}$-equivalents. 


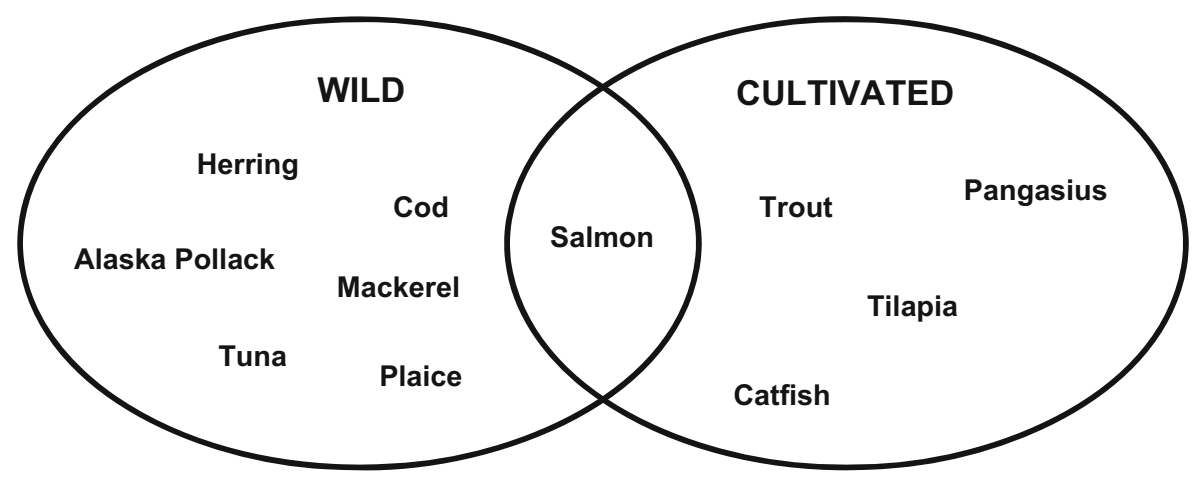

Fig. 1 Consumed fish species in the Netherlands (DNFCS 2007-2010) classified into types of fishery

The relative contributions of the gasses to global warming, i.e., $\mathrm{CO}_{2}$-equivalents, were estimated using guidelines of the International Panel for Climate Change (Blonk et al. 2009; IPCC 2006). Next, land use was determined as environmental impact indicator for fish production. This covers the surface needed for the production during a certain period of time (Blonk 2012). For wild fish, no land use was attributed to the capture of the fish (Blonk et al. 2009). Sustainability labels were included in the analysis to target other environmental aspects, such as biodiversity and depletion of fish stocks.

The amount of GHGE and land use was estimated via life cycle assessments (LCA) for 20 fish products by Blonk Consultants (dataset version 2013). In an LCA, the total amount of emissions and resources used are calculated throughout the whole life cycle of a product (from the production stage to the waste stage); e.g., fish processing, packaging, retail, transport, preparation, storage and disposal. The LCA in this study included also fossil fuel use for both wild and cultivated fisheries (including the production of fish feed) and fish by-catch for the wild fishery. The activities of the consumer, such as transport from grocery store to home, were not taken into account due to large variations and because they can be considered the same for the different species and types of fishery (Blonk 2012). Moreover, preparation and disposal were not taken into account for raw fish products, such as herring. For determination of GHGE and land use of total fish consumption, extrapolations were applied to fish products lacking environmental data. For example, 'salmon pate' was assumed to cover the same amount of GHGE and land use as 'salmon fillet'. Environmental data of other foods was estimated by LCA (dataset Blonk version 2012) as well, to calculate the total daily environmental impact of food consumption. All fish species were evaluated on presence or absence of a sustainability label using current literature (ASC 2014; MSC 2014b; North Sea and World Wide Fund for Nature 2013).

\subsection{N-3 LC-PUFA}

N-3 LC-PUFA (EPA and DHA) and total fat content of fish (and other foods) was available from the Dutch Food Composition Table (NEVO table 2013/4.0) (Dutch Food Composition Database online version 2013). In order to improve reliability and quality of the data, additional information on the EPA and DHA content was collected for the following fish species; herring, Alaska Pollack, cod, tuna, mackerel, plaice, salmon, trout, tilapia, and pangasius. This information was obtained via additional food composition databases (Danish Food Composition 2008; Finish Food Composition Database 2011; Slovenian Food Composition 2013; Swedish Food Composition 2013; USDA National Nutrient Database 
2013) and literature (Anova 2014; ANSES/Ciqual 2012; Bell et al. 1998; Blanchet et al. 2005; Hamilton et al. 2005; Jensen et al. 2012; National Food Agency 2013; National Institute for Health and Welfare Nutrition Unit 2011; Roe et al. 2013; Saxholt 2008; Souci et al. 2013; Strobel et al. 2012; U.S. Department of Agriculture; Agricultural Research Service 2013). Only data originating from food analysis were included. For the remaining fish and other foods, EPA and DHA concentrations were used that were already included in the Dutch Food Composition Database.

\subsection{Statistical analysis}

The average GHGE (in $\mathrm{g} \mathrm{CO}_{2}$-equivalents/day) and land use (in $\mathrm{dm}^{2} /$ day) of the current fish consumption were calculated based on two consumption days. For nutrient intakes, median habitual intakes of EPA and DHA (in mg/day) were calculated from two consumption days using a Logistic Normal Normal (LNN) model, considering correlations between frequency and amount of consumption by the program Monte Carlo Risk Assessment (MCRA edition 8, http://mcra.rivm.nl). The $95 \%$ confidence bounds were estimated using the bootstrap method with 100 iterations. These results were weighted for small deviances in socio-demographic characteristics, days of the week and season of data collection, in order to give results that are representative for the Dutch population. All fish products that were included in the DNFCS and catfish were analysed, except for shellfish.

To evaluate differences in environmental impact and fat composition of various fish species and types of fishery, mean GHGE (in $\mathrm{kg} \mathrm{CO}_{2}$-equivalents $/ \mathrm{kg}$ product), land use (in $\mathrm{m}^{2} *$ year $/ \mathrm{kg}$ product), total fat (in $\mathrm{g} / 100 \mathrm{~g}$ ), n-3 LC-PUFA, EPA and DHA content (in mg/100 g) were calculated for 29 most consumed fish products categorised into 11 fish species. Since food composition data were derived from multiple sources, sample sizes differ per nutrient and fish species. Differences between species were analysed by the Mann-Whitney $U$ test, and differences between types of fishery by the Kruskal-Wallis test. P-values below 0.05 were considered as statistically significant.

\section{Results}

\subsection{Mean environmental impact of current fish consumption}

In the Netherlands, average fish intake was $6.0 \mathrm{~g} /$ day for children and $14.6 \mathrm{~g} /$ day for adults. More than half (53\%) of the consumption is from wild-caught fish, about $20 \%$ from cultivated fish and the unspecified rest mainly from salmon (Table 1). Fish was consumed on $7 \%$ of the days for children and on $16 \%$ of the days for adults. On fish consumption days, the average portion of fish consumed was around 82-90 g. Salmon that could be wild, cultivated or unspecified was the most consumed fish species (in quantity and frequency) in this Dutch population. For the consumption of wild fish, Alaska Pollack (including products such as fish fingers) contributed most in quantity, followed by herring and tuna. Mean GHGE from fish consumption is $89.2 \mathrm{~g} \mathrm{CO}_{2}$-eq. per person per day, which is $2.1 \%$ of the total daily GHGE resulting from food consumption. Mean land use from fish consumption is $3.1 \mathrm{dm}^{2}$ per person per day, which covers $0.7 \%$ of the total land use due to food consumption. Median habitual EPA and DHA intakes from fish are 44.3 (22.7-81.5) $\mathrm{mg}$ and 48.4 (31.4-68.1) $\mathrm{mg}$ per person per day, respectively. 


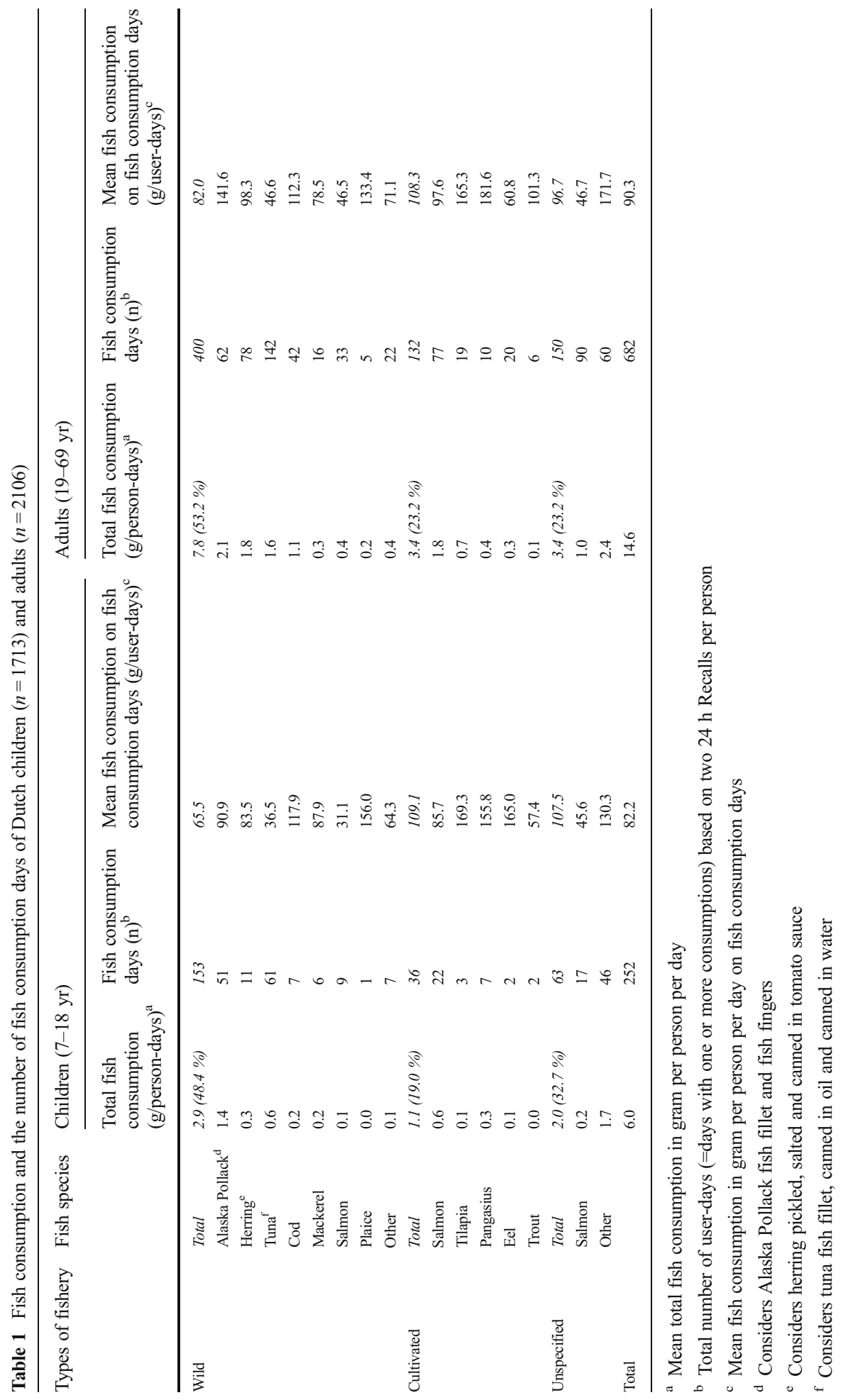




\subsection{Environmental aspects per kg fish}

Table 2 shows the GHGE and land use per kg fish for several fish species and types of fishery (i.e., wild or cultivated). GHGE of wild-caught fish ranged from 1.9 to $18.1 \mathrm{~kg} \mathrm{CO}_{2}$-eq./kg, with approximately a 10-fold difference between species with the lowest (mackerel) and the highest (tuna) value. GHGE of cultivated fish ranged from 3.7 to $15.8 \mathrm{~kg} \mathrm{CO}_{2}$-eq./kg, with salmon with the lowest and tilapia with the highest estimated emissions. The average GHGE was slightly higher for cultivated $(9.6 \mathrm{~kg} \mathrm{CO}$-eq. $/ \mathrm{kg})$ than for wild fish $\left(5.6 \mathrm{~kg} \mathrm{CO}_{2}\right.$-eq. $\left./ \mathrm{kg}\right)(P=0.150)$. Land use was highest for the cultivated species tilapia and pangasius and low for all wild-caught species. Average land use was significantly higher for cultivated fish $\left(4.1 \mathrm{~m}^{2^{*}}\right.$ year $\left./ \mathrm{kg}\right)$ compared to wild fish $\left(0.4 \mathrm{~m}^{2^{*}}\right.$ year $\left./ \mathrm{kg}\right)(P<0.001)$. Considering salmon, which could be wild-caught or cultivated, land use was higher for cultivated $\left(3.1 \mathrm{~m}^{2^{*}}\right.$ year $\left./ \mathrm{kg}\right)$ than for wild-caught $\left(0.6 \mathrm{~m}^{2^{*}}\right.$ year/ $\mathrm{kg}$ ) salmon, but GHGE were comparable (3.7 and $4.0 \mathrm{~kg} \mathrm{CO}$-eq. $/ \mathrm{kg}$ respectively).

Additionally, fishing areas for sustainably caught fish, according to MSC and ASC labels, are shown in Table 2. All wild-caught species, except for mackerel, are available with a MSClabel (March 2014) (MSC 2014b). Among the cultivated fish available on the Dutch market, catfish is not available with an ASC-label and trout is currently under assessment (ASC 2014).

\subsection{Nutritional composition per $100 \mathrm{~g}$ fish}

Total fat, n-3 LC-PUFA, EPA and DHA content varied between the different fish species $(P<0.001$, Table 3$)$. Of the wild species, cod had the lowest n-3 LC-PUFA content $(187 \mathrm{mg}$ per $100 \mathrm{~g}$ ) and mackerel the highest (3621 mg per $100 \mathrm{~g}$ ). Of the cultivated species, tilapia had the lowest n-3 LC-PUFA content (90 mg per $100 \mathrm{~g}$ ). Cultivated salmon had a significantly higher n-3 LC-PUFA content (1631 mg per $100 \mathrm{~g}$ ) compared to wild-caught salmon (1030 mg per $100 \mathrm{~g})(P<0.001)$. Total fat content was two times higher in cultivated salmon. EPA and DHA contents were lowest for tilapia (cultivated), $6 \mathrm{mg}$ and $85 \mathrm{mg}$ per $100 \mathrm{~g}$ respectively, and the highest for mackerel (wild), $1259 \mathrm{mg}$ and $2362 \mathrm{mg}$ per $100 \mathrm{~g}$ respectively.

No statistical differences in EPA and DHA content were found between the types of fishery. Wild fish contained on average $379 \mathrm{mg}$ EPA per $100 \mathrm{~g}$ compared to $447 \mathrm{mg}$ per $100 \mathrm{~g}$ for cultivated fish. The content of DHA for wild fish was $656 \mathrm{mg}$ versus $737 \mathrm{mg}$ per $100 \mathrm{~g}$ for cultivated fish.

\subsection{GHGE and n-3 LC-PUFA combined}

Figure 2 presents an overview of GHGE and n-3 LC-PUFA content of the various fish species in percentages relative to the highest values. Mackerel contains by far the highest amount of n3 LC-PUFA followed by herring and salmon (cultivated). Additionally, these fish species have relatively low GHGE. Tuna contributes most to the GHGE followed by tilapia, trout and catfish. Of the cultivated species, pangasius has low GHGE, but has a high contribution to land use mainly in Asia (Table 2), which is not shown in Fig. 2.

\section{Discussion}

To our knowledge, this study is the first to evaluate the combination of environmental aspects and nutritional composition of fish consumption of the Dutch population. On average, Dutch children consume $6 \mathrm{~g}$ fish and adults $\sim 15 \mathrm{~g}$ fish per person per day. Salmon (wild and 


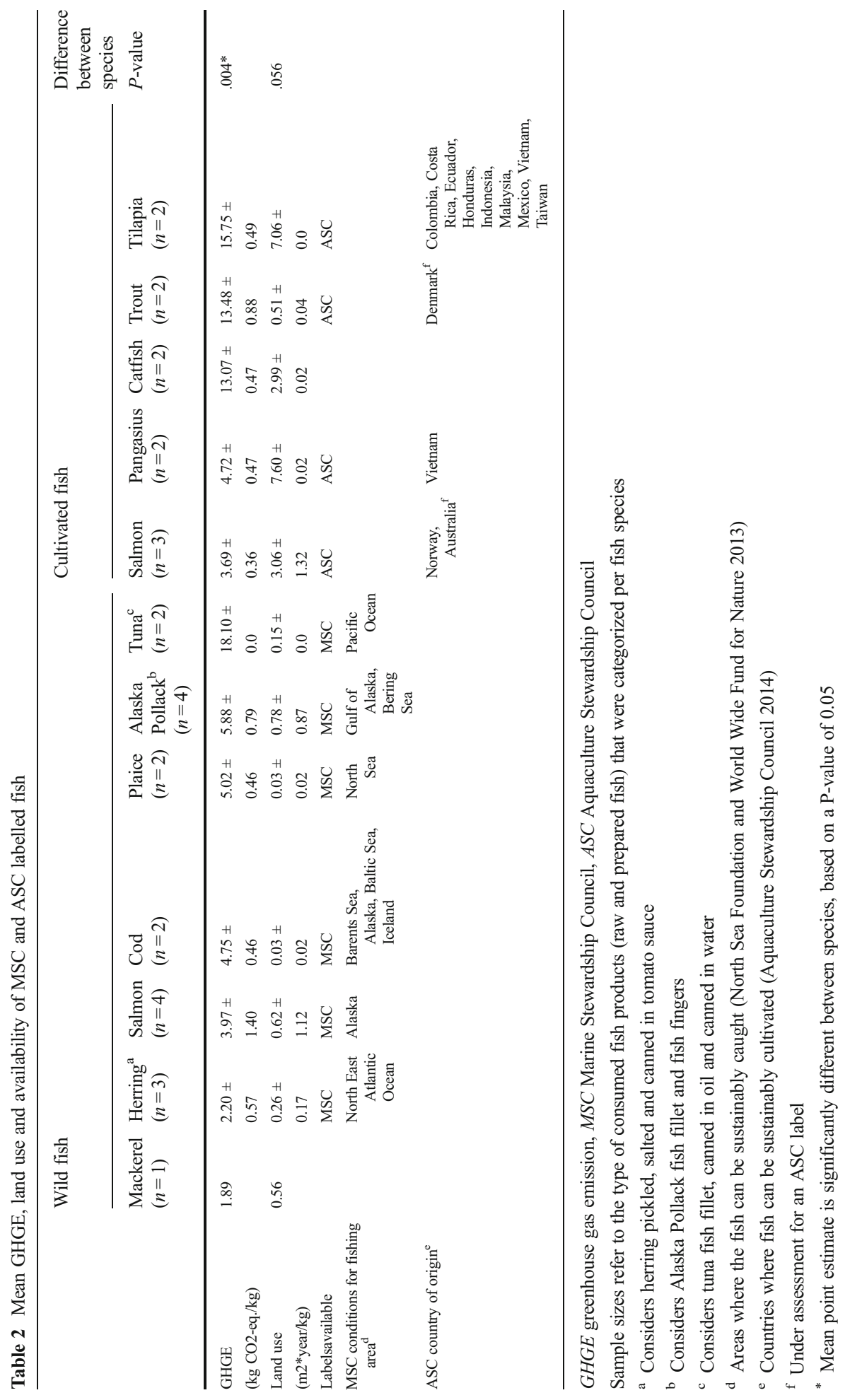




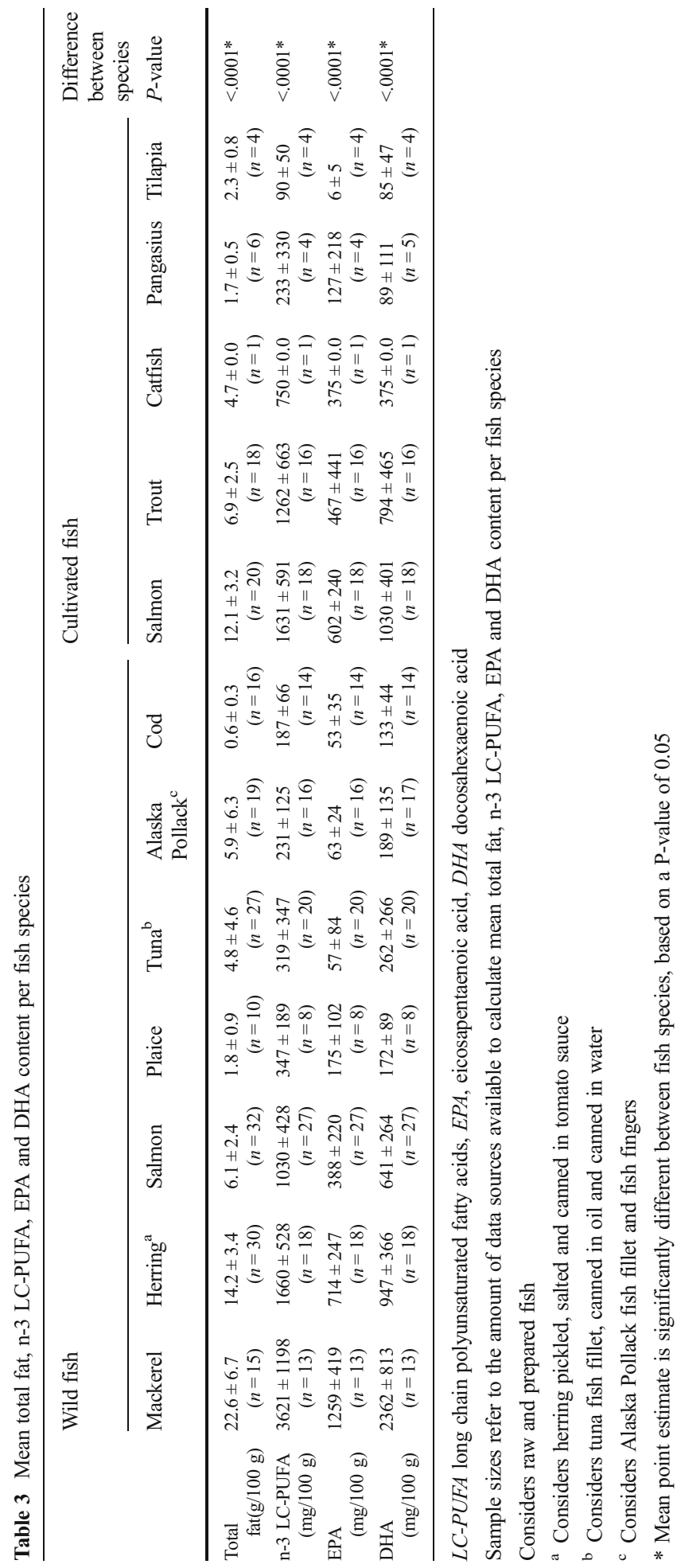


cultivated) contributed most to total fish consumption, followed by the wild-caught fish species Alaska Pollack, herring and tuna. Fish consumption represents only a small part of the total environmental impact of food consumption in the Netherlands, indicated by GHGE and land use. Large variations exist between fish species concerning GHGE and n-3 LC-PUFA content. This is similar for the average cultivated fish compared to wild fish. Land use is higher for cultivated than for wild fish, because of land needed for the production of fish feed as well as for cultivation areas (Blonk et al. 2009; Nijdam et al. 2012). Differences between cultivated species are due to physiological differences. For example, pangasius requires more feed to grow than salmon, which is less efficient in turning feed into fillets (Blonk et al. 2009). Consequently, more land is needed to produce fish feed.

GHGE are significantly different between fish species, indicating a large variety caused by different catching and production methods (Nijdam et al. 2012). For tuna for example, GHGE is high because of the large amount of by-catch during capture, which requires a large amount of energy (FAO 2012).

Other environmental impacts such as biodiversity loss and depletion of fish stocks also contribute to sustainability. These impacts were taken into account via the MSC and ASC labels according to literature, but were not quantified in this study, since consumption data did not contain information on sustainability labelling. Nevertheless, in 2012, sale volumes for sustainably caught and cultivated fish increased by $16.7 \%$ compared to 2011 in the Netherlands (LEI/Wageningen 2013a). Moreover, the monitor on Sustainable Foods revealed that around $85 \%$ of the wild fish supply in Dutch supermarkets was MSC-

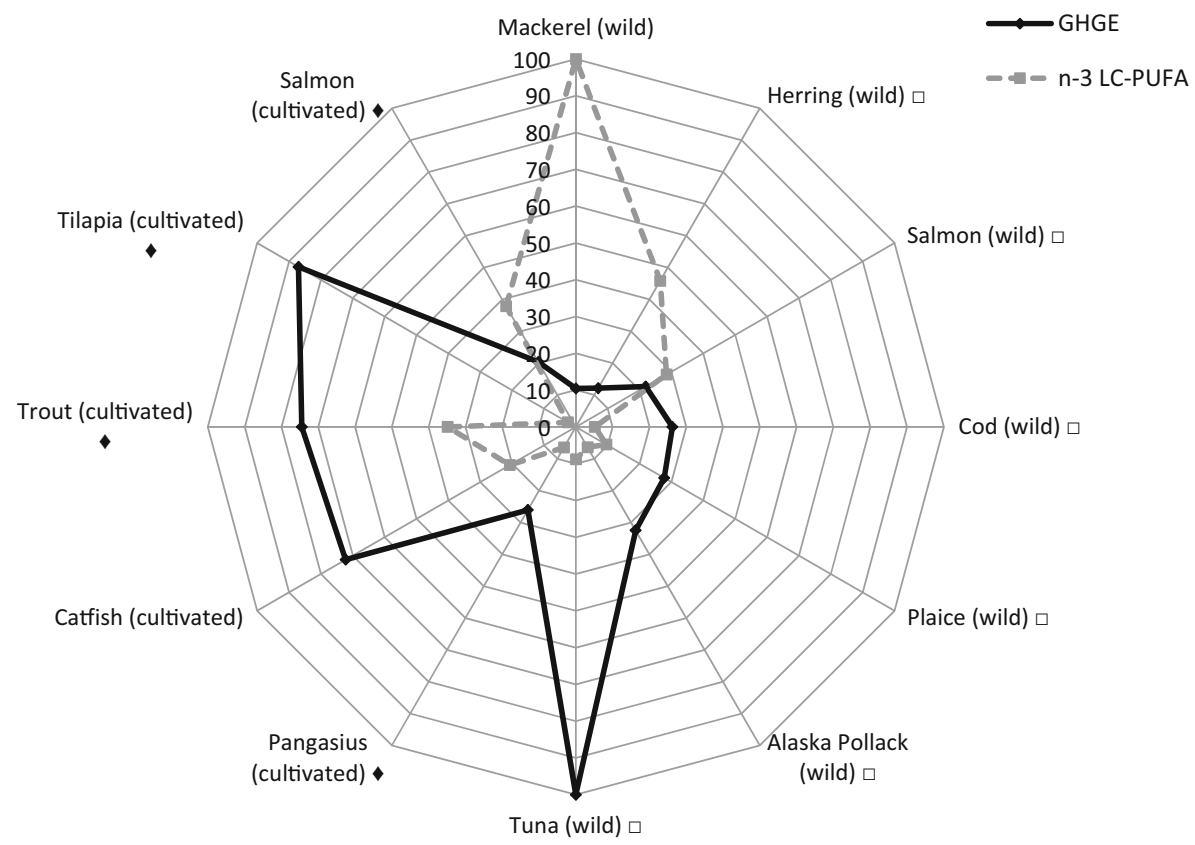

Fig. 2 GHGE and n-3 LC-PUFA of fish species expressed as percentage compared the highest value ${ }^{\mathrm{a}}$ GHGE, greenhouse gas emission; LC-PUFA, long chain polyunsaturated fatty acids; MSC, Marine Stewardship Council; ASC, Aquaculture Stewardship Council ${ }^{\mathrm{a}}$ Tuna had the highest GHGE and mackerel the highest n-3 LC-PUFA content that were both set to $100 \%$. (White square) MSC-label available for wild fish species (Black diamond suit) ACS-label available for cultivated fish species 
certified (LEI/Wageningen 2013b). Overall, 1122 fish products (canned, fresh or frozen) were available with a MSC label on the Dutch market (situation 2014) (MSC 2014a). However, the presence of a sustainability label for a certain species does not necessarily mean that all sold fish of that species is sustainably caught. Sale volumes of ASC-labelled fish are still low, but are expected to increase (ASC 2014; LEI/Wageningen 2013b). Although mackerel emitted fewest GHGE and had low values for land use, the sustainability label has been withdrawn due to depletion of stocks (MSC 2014b). This indicates the importance of considering several environmental indicators.

With regard to the fat composition, EPA and DHA contents differ between fish species related to characteristics, such as body composition, feed and location of origin (Murray and Burt 2001). These variations were large and depend foremost on the kind of species. Note that wild-caught fish are mostly different species than cultivated fish. In general, contents of n-3 LC-PUFA depend on total fat content (Dutch Fish Agency) and is thought to be related to the type of fishery (lower for cultivated fish compared to wild fish) (Harlioğlu et al. 2012; Sérot and Gandemer 1998; Zakeri 2011). The latter was not confirmed by our results. This may be due to our selection of fish species compared to other studies, i.e., turbot, bream and crayfish were not included among the most consumed species in the Netherlands. Furthermore, previous research compared similar fish species with different types of fishery, whereas our study, considered different species with different types of fishery. In our study, salmon is the only species that is wild-caught and cultivated. Cultivated salmon contained considerably more total fat and n-3 LC-PUFA than wild salmon, which is also found by others (Jensen et al. 2012; Strobel et al. 2012). According to Jensen et al. (2012) the fatty acid composition of fatty fish, such as salmon, may be largely determined by the fatty acid composition of the fish feed.

Average fish intake among European countries varies largely according to Roswall et al. (2014), with the highest intakes in Spain and the lowest intakes in the Netherlands and Germany. According to the current Dutch fish consumption, intake of n-3 LC-PUFA is considerably lower than the recommendations (EFSA Panel on Dietetic Products Nutrition and Allergies (NDA) 2010; FAO/WHO 2008). A large part of the Dutch population did not consume fish on the two recalled days. If the recommendation of once a week a portion of (oily) fish would be met, the GHGE due to fish consumption would approximately double. This does not necessary increase total daily GHGE if fish replaces other protein-rich sources with a comparable or higher environmental impact. When comparing mean GHGE and land use per kg product, the environmental impact for an average cultivated or wild fish is lower than for beef, but higher than for pork, chicken, egg, tofu or vegetarian burgers. The fish species in this study with the highest GHGE per kg, tuna and tilapia, are comparable to the GHGE of Dutch beef (Blonk and Luske 2008). Thus, depending on the species, fish may be a favourable choice compared to for example beef, from GHGE, land use and n-3 LC-PUFA perspective.

From the species we evaluated, the wild-caught fish species mackerel and herring and as well as salmon (both wild and cultivated) contain a high amount of n-3 LC-PUFA. These species also have relatively low GHGE and land use. However, mackerel has no sustainability label due to stock depletion (MSC 2014b). Trout (cultivated) is also a large source of EPA and DHA, but has relative high GHGE per kg. No fish species scores best on all indicators. Nevertheless, our results suggest that species such as herring and salmon could be a preferable fish to eat from the combined perspective of consumer health and environment. In order to increase sustainable fish fatty acids intake, alternative sources of 
n-3 LC-PUFA with low environmental impacts may provide another opportunity. For instance, microalgae, the initial n-3 LC-PUFA producers of the food chain may be used for human consumption. Applications exist in infant milk and pharmaceuticals (AdarmeVega et al. 2012). Other possible n-3 LC-PUFA sources are transgenic plants (AdarmeVega et al. 2014) and krill oil, which is already used in supplements (Nichols et al. 2010). A LCA of these alternatives would be required to explore the environmental load of fishing for krill or cultivation of algae and compare this with the LCA's on fish consumption.

Furthermore, environmental impact depends on fishing and farming methods, animal feed for cultivated fish, use of by-catch and side products, transport, storage and packaging, which all include uncertainty ranges. We have tried to make our analysis as representative as possible for the Dutch situation, taking into account all steps from primary production to preparation by the consumer. For the n-3 LC-PUFA concentrations in fish, analytical data from different countries were included in the analysis. The amount of data varied according to species. Finally, other aspects such as information about season of catch and location or country of origin could have improved the quality of composition as well as sustainability data.

\section{Conclusions}

The Dutch population consumes mostly wild compared to cultivated fish species. Our study showed large variations between fish species in GHGE and n-3 LC-PUFA contents. Land use was higher for cultivated fish species due to e.g., the production of fish feed. Our results suggest that herring as well as wild-caught and cultivated salmon with MSC/ASC logo are favourable fish species for consumption, when taking into account both n-3 LC-PUFA content and a selection of direct and indirect environmental indicators. No statement can be made on whether wild-caught or cultivated salmon is preferable from a sustainability point of view. Information from this study may help responsible authorities to develop fish consumption recommendations that are both environmentally sustainable and provide healthy nutritional advice for consumers.

ASC Aquaculture Stewardship Council, DNFCS Dutch National Food Consumption Survey, GHGE greenhouse gas emission, $L C$-PUFA long chain polyunsaturated fatty acids, $L C A$ life cycle assessment, MSC Marine Stewardship Council

Acknowledgments This study was initially performed as a Master thesis by Yvonne the Bekker, which basis was used for writing this manuscript.

Financial support

This work was supported by the Dutch Ministry of Economic Affairs.

\section{Compliance with ethical standards}

\section{Conflict of interest None.}

Authorship MCCB carried out the statistical analysis and prepared the tables and figures. MCCB and SMS wrote the paper, taking into account comments from all the co-authors. EHMT was the overall project coordinator, and initiated and designed this study. EHMT, MCZ, JH, and $\mathrm{AH}$ were members of the writing group and gave input on the statistical analysis and interpretation of the results. All authors provided comments and suggestions on the manuscript and approved the final version. 
Open Access This article is distributed under the terms of the Creative Commons Attribution 4.0 International License (http://creativecommons.org/licenses/by/4.0/), which permits unrestricted use, distribution, and reproduction in any medium, provided you give appropriate credit to the original author(s) and the source, provide a link to the Creative Commons license, and indicate if changes were made.

\section{References}

Adarme-Vega TC, Lim D, Timmins M, Vernen F, Li Y, Schenk PM (2012) Microalgal biofactories: a promising approach towards sustainable omega-3 fatty acid production. Microb Cell Factories 11:96

Adarme-Vega TC, Thomas-Hall SR, Schenk PM (2014) Towards sustainable sources for omega-3 fatty acids production Current Opinion. Biotechnology 26:14-18. doi:10.1016/j.copbio.2013.08.003

Anova Seafood (2014) Nutrition declaration Claresse per 100 g. Anova Seafood BV. http://claresse.eu. Accessed 1rst July 2014

ANSES/Ciqual French food composition table (2012) http://www.afssa.fr/TableCIQUAL/.

ASC (2014) Aquaculture Stewardship Council; Certified Seafood. Aquaculture Stewardship Council. http:// www.asc-aqua.org/. Accessed 24th of April 2014

Ascherio A, Rimm EB, Stampfer MJ, Giovannucci EL, Willett WC (1995) Dietary Intake of Marine n-3 Fatty Acids, Fish Intake, and the Risk of Coronary Disease among Men. N Engl J Med 332:977-983. doi:10.1056/ NEJM199504133321501

Bell JG, McEvoy J, Webster JL, McGhee F, Millar RM, Sargent JR (1998) Flesh lipid and carotenoid composition of Scottish farmed Atlantic salmon (Salmo salar). J Agric Food Chem 46:119-127. doi:10. $1021 /$ jf970581k

Blanchet C, Lucas M, Julien P, Morin R, Gingras S, Dewailly É (2005) Fatty acid composition of wild and farmed Atlantic salmon (Salmo salar) and rainbow trout (Oncorhynchus mykiss). Lipids 40:529-531. doi: $10.1007 /$ s11745-005-1414-0

Blonk H (2012) The Agri-footprint method. Methodological LCA framework, assumptions and applied data. Blonk Consultants, Gouda

Blonk H, Luske B (2008) Greenhouse gas emissions of meat methodological issues and establishment of an information infrastructure - background document. Blonk Consultants, Gouda

Blonk H, Luske B, Kool A (2009) Environmental effects of several popular fish species (in Dutch). Blonk Consultants, Gouda

Danish Food Composition Databank (2008) Department of Nutrition, National Food Institute, Technical University of Denmark: http://www.foodcomp.dk/v7/fcdb_default.asp.

Dutch Fish Agency Fish and Health (in Dutch). Dutch Fish Agency, Rijswijk

Dutch Food Composition Database online version 2013/4.0 (2013) The National Institute for Public Health and the Environment: http://nevo-online.rivm.nl/.

EFSA Panel on Dietetic Products Nutrition and Allergies (NDA) (2010) Scientific Opinion on Dietary Reference Values for fats, including saturated fatty acids, polyunsaturated fatty acids, monounsaturated fatty acids, trans fatty acids, and cholesterol vol 8 (3). EFSA

FAO (2012) The state of the world fisheries and aquaculture 2012. Food and Agriculture Organization of the United Nations, Rome

FAO (2014) The state of wild fisheries and aquaculture opportunities and challenges. Food and Agriculture Organization of the United Nations, Rome

FAO/WHO (2008) Fats and Fatty Acids in Human Nutrition, Report of a joint expert consultation Food and Nutrition Paper 91

Fineli. Finnish food composition database (2011).

Garnett T (2008) Cooking up a storm: Food, greenhouse gas emissions and our changing climate. Centre for Environmental Strategy, University of Surrey

Garnett T (2013) Food sustainability: problems, perspectives and solutions. Proc Nutr Soc 72:29-39. doi:10. $1017 / \mathrm{s} 0029665112002947$

Goñi R (1998) Ecosystem effects of marine fisheries: an overview ocean. Coast Manag 40:37-64

Hamilton MC, Hites RA, Schwager SJ, Foran JA, Knuth BA, Carpenter DO (2005) Lipid Composition and Contaminants in Farmed and Wild Salmon Environmental Science. Technology 39:8622-8629. doi:10. 1021/es050898y

Harlioğlu AG, Aydin S, Yilmaz Ö (2012) Fatty acid, cholesterol and fat-soluble vitamin composition of wild and captive freshwater crayfish (Astacus leptodactylus). Food Sci Technol Int 18:93-100. doi:10.1177/ 1082013211414261 
He K, Song Y, Daviglus ML, Liu K, Van Horn L, Dyer AR, Greenland P (2004a) Accumulated evidence on fish consumption and coronary heart disease mortality: a meta-analysis of cohort studies. Circulation 109:27052711. doi:10.1161/01.cir.0000132503.19410.6b

He K et al (2004b) Fish consumption and incidence of stroke: a meta-analysis of cohort studies. Stroke J Cere Circ 35:1538-1542. doi:10.1161/01.str.0000130856.31468.47

Health Council of the Netherlands (2015) Guidelines for a healthy diet 2015. Health Council of the Netherlands, The Hague

IPCC (2006) 2006 IPCC guidelines for national greenhouse Gas inventories, prepared by the national greenhouse Gas inventories programme. IGES, Japan

IUCN (2015) European Red List of Marine Fishes. International Union for Conservation of Nature (IUCN) and European Commission, Luxembourg

Iwama GK (1991) Interactions between aquaculture and the environment. Crit Rev Environ Contr 21:177-216

Jensen IJ, Mæhre HK, Tømmerås S, Eilertsen KE, Olsen RL, Elvevoll EO (2012) Farmed Atlantic salmon (Salmo salar L.) is a good source of long chain omega-3 fatty acids. Nutr Bull 37:25-29. doi:10.1111/j.1467-3010.2011.01941.x

LEI/Wageningen University (2013a) Monitor Sustainable Foods 2012 (in Dutch). Ministry of Economic Affairs The Hague

LEI/Wageningen University (2013b) Monitor Sustainable Foods (in Dutch). http://www.monitorduurzaamvoedsel. nl/Default.aspx

Marine Stewardship Council: Sustainable seafood product finder (2014a). Accessed 24-11-2014

Mirto S et al (2010) Fish-farm impact on metazoan meiofauna in the Mediterranean Sea: analysis of regional vs. Habitat effects. Mar Environ Res 69:38-47

MSC (2014b) Marine Stewardship Council; Certified Sustainable Seafood. Marine Stewardship Council. http:// www.msc.org/. Accessed 24th of April 2014

Murray J, Burt JR (2001) The Composition of Fish. FAO in partnership with Support unit for International Fisheries and Aquatic Research

Naylor RL et al (2009) Feeding aquaculture in an era of finite resources. Proc Natl Acad Sci U S A 106:1510315110. doi:10.1073/pnas.0905235106

Nichols PD, Petrie J, Singh S (2010) Long-chain omega-3 oils-an update on sustainable sources. Nutrients 2: 572-585. doi:10.3390/nu2060572

Nijdam D, Rood T, Westhoek H (2012) The price of protein: review of land use and carbon footprints from life cycle assessments of animal food products and their substitutes. Food Policy 37:760-770. doi:10.1016/j. foodpol.2012.08.002

North Sea Foundation, World Wide Fund for Nature (2013) VISwijzer 2013-2014 (in Dutch).

Osler M, Andreasen AH, Hoidrup S (2003) No inverse association between fish consumption and risk of death from all-causes, and incidence of coronary heart disease in middle-aged, Danish adults. J Clin Epidemiol 56: 274-279. doi:10.1016/S0895-4356(02)00600-5

Raatz S, Silverstein J, Jahns L, Picklo M (2013) Issues of fish consumption for cardiovascular disease risk reduction. Nutrients 5:1081-1097

Roe M, Church S, Pinchen H, Finglas P (2013) Nutrient analysis of fish and fish products Analytical Report. Department of Health, London

Roswall $\mathrm{N}$ et al (2014) Consumption of predefined 'Nordic' dietary items in ten european countries - an investigation in the european prospective investigation into cancer and nutrition (EPIC) cohort. Public Health Nutr 17:2650-2659. doi:10.1017/S1368980014000159

Sérot T, Gandemer G, Demaimay M (1998) Lipid and fatty acid compositions of muscle from farmed and wild adult turbot. Aquac Int 6:331-343. doi:10.1023/a:1009284905854

Slovenian Food Composition Database (2013).

Strobel C, Jahreis G, Kuhnt K (2012) Survey of n-3 and n-6 polyunsaturated fatty acids in fish and fish products. Lipids Health Dis 11:1-10. doi:10.1186/1476-511X-11-144

Swedish Food Composition Database (2013) http://www.slv.se/en-gb/Group1/Food-and-Nutrition/The-Food-Database/. USDA National Nutrient Database for Standard Reference (2013)

Van Rossum CTM, Fransen HP, Verkaik-Kloosterman J, Buurma-Rethans EJM, Ocke MC (2011) Dutch National Food Consumption Survey 2007-2010: Diet of children and adults aged 7 to 69 years. The National Institute for Public Health and the Environment (RIVM), Bilthoven

Westhoek H, Rood T, van de Berg M, Janse J, Nijdam D, Reudink M, Stehfest E (2011) The protein puzzle: the consumption and production of meat, dairy and fish in the european union. PBL Netherlands Environmental Assessment Agency, The Hague

Wu RSS (1995) The environmental impact of marine fish culture: towards a sustainable future. Mar Pollut Bull 31:159-166

Zakeri M (2011) Variations in lipid content and fatty acids composition in wild and cultured Yellowfin Seabream Acanthopagrus latus in the Persian Gulf. J Persian Gulf 2:53-61 